\title{
SOBRE CRIANÇAS E ENCONTROS: SINGULARIDADES EM JOGO NA ESTÉTICA CINEMATOGRÁFICA
}

\author{
Fabiana de Amorim Marcello
}

\begin{abstract}
RESUMO: Neste trabalho, discuto as noções de encontro, de composição e da função anômalo, tais como descritas por Deleuze e Guattari (2002). O objetivo aqui é pensar na criança singular, na criança-acontecimento, quando atravessada, cinematograficamente, por uma potência desestabilizadora, expressa pela figura do pária. Para tanto, analiso os filmes $O$ garoto, de Charles Chaplin (1921), e $O$ menino selvagem, de François Truffaut (1970), mostrando de que maneira os próprios conceitos vão sendo tecidos a partir das análises fílmicas. No que diz respeito à imagem da criança, tais conceitos nos permitem pensar que não interessa o que é melhor ou pior, em que estágio está, de que espécie é, se é fiel ou não a um modelo (de) infantil (pedagógico? Sociológico? Psicológico?); interessa saber, afinal, do encontro entre John e Carlitos, entre Victor e Itard, o que se produz de novo? Que singularidades são produzidas aí? É em torno destas perguntas que as análises são feitas.
\end{abstract}

Palavras-chave: Criança. Cinema anômalo. Composição.

ON CHILDREN AND ENCOUNTERS: SINGULARITIES AT STAKE IN CINEMA AESTHETICS

ABSTRACT: This essay discusses the notions of encounter, composition and anomalous function, as described by Deleuze and Guattari (2002). It reflects upon singular children, childrenevents, when, in a movie, they come upon a destabilizing power, expressed by the figure of the pariah. Its analyses of Chaplin's The kid (1921) and Truffaut's L'enfant sauvage (1970) show how movie analyses weave concepts. As for the image of children, such

Doutora em Educação e professora do Programa de Pós-Graduação em Educação da Universidade Luterana do Brasil (UlBRA).E-mail: famarcello@gmail.com 
concepts allow us to think that it is irrelevant to inquire what is best or worst, in what stage it is, whether or not it is faithful to an (educational? sociological? psychological?) model of children. Interesting here is to find out what is new in the encounters between John and The Tramp, and Victor and Itard. What singularities do they produced? Such questions guide our analyses.

Key words: Child. Movie anomalous. Composition.

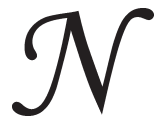

este trabalho, ${ }^{1}$ discuto as noções de encontro, de composição e, especialmente, aquela ligada à função anômalo, tais como descritas por Deleuze e Guattari (2002). Para tanto, analiso os filmes $O$ garoto, de Charles Chaplin (1921), e $O$ menino selvagem, de François Truffaut (1970). Interessa-me aqui debater em que medida podemos pensar na criança singular, na criança-acontecimento, a partir do momento em que ela é atravessada, cinematograficamente, por uma potência desestabilizadora, expressa pela figura do pária, do indivíduo excepcional, limítrofe.

Busco compreender como, neste encontro, a criança é afetada e de que maneira ela afeta outrem. Assim, poderíamos perguntar: ao encontrar-se com outrem, como se dá sua capacidade de agir? Ao encontrar-se com Dr. Itard, como se dá a capacidade de agir de Victor, o menino selvagem? Ou, tratando-se do encontro do adulto com a criança, como se dá a capacidade de agir para Carlitos - talvez um dos exemplos mais emblemáticos do anômalo no cinema? É quando uma questão de dinâmica (de atividade) entra em jogo que o acontecimento tem lugar, porque ele (o acontecimento) é "sempre produzido por corpos que se entrechocam, se cortam ou se penetram, a carne e a espada" (Deleuze \& Parnet, 1998, p. 78). Contudo, o efeito que nasce daí não é da ordem dos corpos, mas, antes, diz respeito a uma "batalha impassível, incorporal, impenetrável, que domina sua própria realização e domina sua efetuação" (Deleuze \& Parnet, 1998, p. 78). Nenhum esoterismo, mas apenas a noção de que é a partir do encontro que as forças se manifestam e que o acontecimento tem lugar - de modo que aquilo que resulta de um encontro é invariavelmente singular.

Quais os deslocamentos, quais os "ganhos" que teríamos ao perguntarmos acerca do tipo de universo que se abre quando o encontro com o anômalo é fator capital para as análises desses filmes? Com o 
que nos defrontamos nesse universo do encontro que, aos olhos do mundo das coisas prontas, das formas previsíveis e independentes, nos seria invisível? Ao perguntarmos o que acontece, por exemplo, quando os elementos heterogêneos da criança conjugam-se com outros elementos heterogêneos ou, talvez, quando a zona de vizinhança entre a criança e o anômalo (ou a criança ela mesma anômala) é traçada, ficamos cada vez mais distantes de noções de desenvolvimento, de ideias de representação - e é aí que reside grande parte dos deslocamentos desse tipo de análise. Isso porque nunca sabemos o que resulta de um encontro, já que ele é, em sua essência, da ordem do imprevisível (só se sabe o que ele é no momento mesmo em que ele se dá).

No que se refere ao debate sobre estas questões, primeiramente, situo a discussão acerca dos conceitos de multiplicidade, função anômalo e encontro, e o faço a partir das elaborações de Deleuze e Guattari, como já referido anteriormente. Em seguida, mostro de que maneira os próprios conceitos vão sendo tecidos e desenvolvidos a partir da análise das imagens dos filmes em questão. Ou seja, mais do que tomar os conceitos como "prontos", importa mostrar de que maneira eles são tensionados quando postos a operar nas análises cinematográficas. No que diz respeito à imagem da criança, tais conceitos nos permitem pensar que não interessa o que é melhor ou pior, em que estágio está, de que espécie é, se é fiel ou não a um modelo infantil (pedagógico? Sociológico? Psicológico?); interessa saber, afinal, do encontro entre John e Carlitos, entre Victor e Itard, o que se produz de novo? $\mathrm{O}$ que de inesperado surge? Quais as fulguraçôes que esses encontros favorecem? Eles dizem algo do acontecimento? Que singularidades são produzidas aí? Como a criança irrompe e se transforma nesse encontro-acontecimento? É em torno destas perguntas que as análises são feitas.

Multiplicidade, encontro e função anômalo: dos modos de ver a criança

Como suspender uma vontade de abarcar a infância e, no lugar disso, apostar na conjugação das forças ativas e imprevisíveis da criança? Como descrever, como discorrer ou mesmo como contemplar um elemento tão sutil, e por isso fugaz, que atravessa uma vida, que a singulariza, e que, ao mesmo tempo, não permite que ela seja 
individualizada (ou assujeitada, no sentido de fazer dela resultado, efeito de um sujeito, de um corpo)? Como descrever esse elemento singularizador, sem favorecer uma noção que resuma e limite a criança na afirmação totalizadora de "as crianças são" (brincalhonas, engraçadas, ternas, etc.)?

Em relação a isso, vale mencionar a discussão sobre a singularidade radical a partir da figura do bebê, tal como desenvolvida por Stéfan Leclerq (2002). No texto "Deleuze e os bebês", o autor traduz todo o caráter de indeterminação do infantil, afirmando que "a vida (...) se encarna na figura do bebê", uma vez que ele é inteiramente "singularidade pré-individual” (Leclerq, 2002, p. 23). Segundo o autor, podemos afirmar que "todos os bebês se parecem, embora eles mostrem expressóes que os atravessam inteiramente, como um sorriso ou uma careta" (idem, ibid.). Tais expressões são "a manifestação de uma vida que percorre e singulariza o bebê, sem individualizá-lo"; expressôes que fazem dele algo "que pertence apenas ao sensível" (idem, ibid.; grifos meus). Essa vida que se encarna no bebê é vida imanente, "pura potência, e até mesmo beatitude" (Deleuze, 2002, p. 14). Nesta perspectiva, os recém-nascidos não têm individualidades ou qualquer outro elemento que os individualize (Leclerq, 2002).

Talvez, então, devamos falar não em uma vontade de abarcar a infância, mas numa vontade de imanência (Héber-Suffrin, 2003) da criança. Vontade de imanência da criança significaria qualquer recusa a um elemento ou mundo transcendente. No que diz respeito aos filmes escolhidos, portanto, não interessa descrever a criança que a infância realizou, entendida como criança transcendente, pois esta se apoia na criação e atualização dos dualismos advindos de noções de verdadeiro e de falso ("verdadeira" criança), de mais e de menos (ser "mais criança", "menos" criança). A criança, assim, estaria relacionada com a finalidade, com a possibilidade (ou com o total fracasso) de efetuar-se em sua plenitude. Antes disso, trataremos da vontade de imanência da criança como algo que existe em si mesmo, que não está nem mesmo localizado na criança (mas no encontro estabelecido com outrem), que não depende ou não pertence a ela, mas que a própria criança, como pura potência de vida, existe na imanência.

Como pensar, então, nessa imanência e não na transcendência? Para tanto, efetuarei a discussão de um modo muito particular, qual 
seja, buscando privilegiar três aspectos no que diz respeito às análises cinematográficas da criança: primeiro, o fato de a criança sempre dizer respeito a uma multiplicidade; domínio (da multiplicidade) que, para Deleuze e Guattari (2002), está necessariamente caracterizado pela composição entre partes ou elementos (assim, o segundo aspecto relaciona-se à compreensão acerca das disposições entre a criança e aquele com o qual ela se relaciona nos filmes); e, por fim, a consideração de que a criança diz respeito àquilo que chamaremos aqui de função anômalo.

Propor uma análise da imagem da criança em função das multiplicidades das quais ela faz parte configura-se como uma tentativa de afastamento da noção de identidade. Ou seja, ao invés de pensarmos no ponto de convergência de uma identidade reconhecível el ou a ser reconhecida, em que características de uma criança repousariam tranquilamente, trata-se de efetuar um deslocamento em favor justamente da sua dispersão. Com o conceito de multiplicidade, são eliminadas características como as de unicidade, permanência, fixidez, universalidade. Assim, cabe aqui compreender a multiplicidade concreta que envolve a criança como um conceito ao mesmo tempo pluralista e dinâmico, uma vez que "cada elemento de uma multiplicidade varia sem cessar, modifica sua distância em relação aos outros" (Deleuze \& Guattari, 2000, p. 44).

O que importa para a análise, portanto, é em que medida a multiplicidade se apresenta como tal e, assim, coloca em jogo um conjunto de elementos heterogêneos para sua composição. Dessa maneira, a criança será concebida aqui como pertencente ao domínio de uma multiplicidade do tipo intensiva. Não é a criança que é múltipla, ela, antes, atravessa esse tipo de multiplicidade (intensiva-a). Entendida dessa forma, a criança deixa de ser um pólo aglutinador e passa a ser “(...) um campo de forças, de intensidades, de relações diferenciais, de elementos indiferenciados (...)” (Silva, 2004, p. 137). Nessa multiplicidade, o que interessa são as forças que agem e reagem - e como elas o fazem. Por atravessar um "campo formado de elementos contínuos (não podem ser concebidos como exteriores uns aos outros, como separados espacialmente) e heterogêneos (uma força, por exemplo, não é equivalente à outra)" (idem, ibid.), o que acontece acontece ali, naquele momento e em nenhum outro mais, pois o que acontece acontece em 
função das disposições, das combinaçôes que estão ali e em nenhum outro lugar. Por isso se diz da multiplicidade intensiva que, ao dividirse, muda de natureza: ao dividir-se - e caberia melhor falar em "desdobrar-se" -, "ficamos, necessariamente, com 'conjuntos' cujos elementos são de natureza diferente dos elementos originais" (idem, p. 136-137). Tal assertiva é cara a esta discussão, na medida em que entendemos que a análise em si dará conta de descrever um conjunto de elementos de uma multiplicidade desse tipo.

"As relaçôes, as determinações espaciotemporais não são predicados da coisa, mas dimensões de multiplicidades [intensivas]" (Deleuze \& Guattari, 2002, p. 50). A partir dessas consideraçōes, talvez seja possível dizer que há uma multiplicidade em jogo quando vemos a imagem da criança que cria o seu mundo e que pode ser vista também em outros filmes. Valentin (Agresti, 2002), em seus ensaios para uma futura carreira de astronauta. Ingemar (Hallström, 1985), em sua casa-esconderijo. Jean e Pierrete (Feyder, 1925) e a pequena ilha que constroem à beira do rio. Léolo (Lauzon, 1992), em sua crença de ser filho de um tomate italiano, de abrir a janela do seu quarto e, em meio aos edifícios vetustos de um subúrbio em Montreal, ver os campos mais verdes da Itália mediterrânea. Não se trata da criança que finge ser astronauta, brinca "de casinha", que finge ter sua própria casa, que finge estar em uma ilha e ser dona dela: é a criança que, por dizer respeito a uma multiplicidade do tipo intensivo, $e$ astronauta, ela $e ́$ a casa, a ilha, a Itália - mas, ao mesmo tempo, não é nenhuma dessas coisas. É esse entre-lugar que nos interessa, pois é dele que partem a possibilidade única e irrepetível da criação e o modo pelo qual as crianças se tornam irredutíveis umas às outras.

Obviamente, não há nenhum projeto para que finalmente toda criança venha a ser criança-acontecimento. A questão é que sempre se está (ou elas estão) no caminho entre uma e outra, no caminho entre a determinação e a indeterminação, entre o que é da ordem do estado de coisa e do acontecimento. Criança empírica, corpo, materialidade em relação à criança-acontecimento, "quarta pessoa do singular" (Deleuze \& Parnet, 1998, p. 78), criança-fulguração, entre o é e o não é. Podese dizer com isso que, sempre oscilantes, as crianças são contínuas umas em relação às outras. Uma necessita da outra para manifestar existência e, além disso, facilmente uma pode se transformar na outra, sem que 
isso suponha um processo de exclusão. Daí a possibilidade de pensarmos: "Não será preciso guardar um mínimo de estratos, um mínimo de formas e de funçôes, um mínimo de sujeito" para que deles pudéssemos extrair aquilo que, de algum modo, seria da ordem do acontecimento? (Deleuze \& Guattari, 2002, p. 60).

Imersa em multiplicidades, composta por elas e atravessando-as, a criança será considerada então sob um ponto de vista da relação, do encontro e da composição entre suas partes, entre seus elementos. Como se pode observar, encontro e composição são, de fato, conceitos profundamente relacionados, e, arrisco-me a dizer, inseparáveis. Entende-se por composição (ou composições) as singularidades que emergem a partir de um encontro. Daí, podermos perguntar: há composição sem encontro. Certamente que não? Há encontro sem composição? Definitivamente, espera-se que não.

Assim, em certa medida, talvez se possa afirmar que se tratará, neste texto, de realizar a análise das composiçôes em jogo em dois filmes específicos; uma análise cuja pergunta-guia poderia ser assim formulada: como a criança-imagem se compõe com elementos outros e, no seio dessa relação, como ela se torna criança-acontecimento? Tal pergunta converge para a tarefa não de analisar o que a criança é efetivamente, quais são suas características, mas como ela se compõe com outras, consigo mesma e o que deriva daí (não em termos de resultados, de produtos ou de saberes, mas em termos de aumento ou diminuição da capacidade de agir). Interessa-nos, portanto, compreender a criança mais no momento em que está ligada à noção de aliança do que propriamente no de filiação (Deleuze \& Guattari, 2002).

Em Deleuze e Guattari (2002), as noções de multiplicidade e de encontro reúnem-se de modo singular por meio da figura do anômalo. Pensar no anômalo - que aqui será considerado aquele que está numa posição anômala, que exerce uma função anômala, ou mesmo que é uma potência anômala - é pensar num "indivíduo excepcional" (Deleuze \& Guattari, 2002, p. 25), com o qual se deve fazer aliança para sair da ordem do ser e entrar no espaço indiscernível do ser-não ser. Anômalo nada tem a ver com anormal. Ao passo que o anormal é definido em função de suas características em relação a uma norma que o individualiza, o anômalo é "uma posição ou um conjunto de posições em relação a uma multiplicidade” (idem, p. 26). 
As noções de multiplicidade e de encontro conjugam-se na medida em que uma cresce em função da outra: quanto mais variados forem os elementos de determinada composição, mais dimensōes estarão em jogo numa multiplicidade. Daí a importância do anômalo como categoria de análise: é ele que, de algum modo, vai conduzir, na relação com a criança, os limites da multiplicidade. $\mathrm{O}$ anômalo não é apenas a figura que diz respeito ao limite, à borda: ele próprio é um fenômeno de borda, "linha que envolve ou é a extrema dimensão em função da qual se pode contar as outras" (Deleuze \& Guattari, 2002, p. 27). Se o anômalo é a borda, ao compreendê-lo podemos igualmente melhor compreender a multiplicidade que ele bordeja. Ir além ou ficar aquém da diagonal que o anômalo traça significa dizer que estaríamos nos ocupando com uma multiplicidade de outra natureza (Deleuze $\&$ Guattari, 2002) - pois os elementos que estariam dispostos seriam outros, assim como as velocidades e as potências de agir.

Em relação a essa função anômalo e ao conceito em questão, poderíamos perguntar se é o anômalo que define a criança ou a criança que define o anômalo. Nem um nem outro: anômalo e criança definem-se mutuamente, na composição de suas partes. Assim, Mohammad Reza é o anômalo em Onde fica a casa do meu amigo? (Kiarostami, 1987), que precipita em Ahmad a busca fremente pelo imprevisível. $\mathrm{O}$ anômalo é a potência desestabilizadora: é Saga para Ingemar (Hallström, 1985), Jean Bonnet para Jean Quentin (Malle, 1987), David para Martin (Spielberg, 2001). Entre o anômalo e a criança a relação não é de identificação; os dois tornam-se outra coisa quando do seu encontro e é dele que a criança como singularidade irrompe: da zona de vizinhança que se estabelece entre anômalo e criança. Jesus para Marcelino (Vajda, 1954), Don Gregório para Totó (Tornatore, 1988), Rufo para Valentin (Agresti, 2002), Sueli para Pixote (Babenco, 1981). Até mesmo a guerra pode também exercer essa função anômalo, como para Edmund (Rosellini, 1947), Ivan (Tarkovsky, 1962), Bill Sebastian (Boorman, 1987). Ou mesmo o pequeno peixe dourado para Razieh (Panahi, 1995), o cavalo branco para Giuseppe e Pasquale (De Sica, 1946), a baleia para Keisha (Caro, 2003) ou o perseguidor balão vermelho para Pascal (Lamorisse, 1956).

Assim, interessa-nos capturar o anômalo como função, ou seja, entendendo que, sendo adulto, criança ou animal, é a partir de sua 
condição de anômalo que se traçam linhas de força, as quais, no encontro com a criança, produzirão (ou não) a criança-acontecimento. É por meio dessa função de anomalia que o anômalo permite o surgimento da criança e não do fato de o anômalo ser ou não (outra) criança. Pode-se afirmar, portanto, que é somente na relação entre criança e anômalo, no encontro que ambos estabelecem, na aliança que é tecida entre eles, que a criança se transmuta em criança-acontecimento. No processo de análise, portanto, terá primazia a explicitação da condição de anomalia, pois é isso que define as diferenças de grau e de natureza das multiplicidades que estarão em jogo entre as crianças dos diferentes materiais. Importa agora verificarmos as multiplicidades, os encontros entre esse anômalo que é Carlitos e o menino John; as multiplicidades e os encontros entre essa criança anômala que é Victor e o Dr. Itard.

\section{O garoto e $O$ menino selvagem: anômalos, multiplicidades e encontros}

Carlitos: talvez a expressão mais direta do anômalo, do pária, daquele que se distingue dos demais de sua "espécie". Uma mistura de vagabundo, maltrapilho, palhaço, mímico. Figura capital do cinema, Carlitos não é apenas um marginal, ele é "o mais marginal dos marginais” (Truffaut, 2000, p. 13; trad. minha). O personagem consegue reunir, a um só tempo, o riso e a emoção. Dos mais de 15 filmes protagonizados por Carlitos, de fato, apenas alguns se tornaram mais emblemáticos - mas foram suficientemente capazes de imortalizar a figura desse outsider: Uma vida de cão (1918), O garoto (1921), O circo (1928), Luzes da cidade (1931), Tempos modernos (1936). Carlitos de mil faces. O personagem de Charles Chaplin é ainda hoje identificado com o próprio cinema. Quem não conhece o andar de pato, a bengala, o fraque furado, as calças levemente caídas, a despretensiosa cartola, os sapatos gastos e, especialmente, o bigode em forma de trapézio? "É a humanidade inteira que se equilibra nas pernas frágeis de Carlitos" (Merten, 2005, p. 60).

O pseudo-herói Carlitos nunca teve suas formas plenamente definidas, já que sempre prestes a ser encarnado numa outra história, repaginado. A presença de $\mathrm{M}$. Verdoux (O barba azul - 1947) desestabiliza a figura do vagabundo, torna-se seu martírio: Carlitos, "fantasiado 
Sobre crianças e encontros: singularidades em jogo na estética cinematográfica

de seu avesso", surge aqui "na condição de sobreimpressão" em M. Verdoux (Bazin, 2000, p. 44; trad. minha). Carlitos-Verdoux: "se Carlitos sofre de um evidente complexo de inferioridade em relação ao outro sexo, Verdoux assume o papel de Don Juan e com sucesso (...); Carlitos é terno e inocente, Verdoux é um cínico (...). Carlitos tem em sua essência a inadequação social, Verdoux a superadaptação; a polícia que aterroriza Carlitos é facilmente enganada por Verdoux, aliás, é a polícia que tem medo dele" (idem, p. 45-46; trad. minha). Quem é Adenoid Hinkel, em O grande ditador (1940)? "Por ter-lhe roubado o bigode, Hitler entregou-se de pés e mãos atados para Carlitos" (idem, p. 32; trad. minha). Hitler toma de Carlitos o bigode, Carlitos, então, retoma seu bigode e faz dele, agora, um bigode à la Hitler. Em vez de matar seu adversário, Carlitos o enfraquece: Hinkel não nos inspira o ódio, a raiva ou o medo, mas o ridículo, a ironia, a partir da introdução do burlesco. Já não se sabe mais o que caracteriza Carlitos: ser um vagabundo? O bigode? $\mathrm{O}$ andar de pato? Não se trata de respostas, não se trata de fixar o personagem, encerrando-o num conjunto demarcado de características, mas de saber que ele é todos e nenhum, ao mesmo tempo.

O que se observa, por certo, é o fato de que Carlitos se relaciona de modo muito particular tanto com o universo de caracterização do personagem como com temáticas pungentes do seu tempo e que, exatamente por isso, fizeram-se perenes (tanto o personagem em si como a vida que dele deriva a partir da problematização dos "tempos modernos”). Carlitos no circo, Carlitos como limpador de vidraças, como palhaço, como milionário, como apaixonado e, em meio a isso, encontramos Carlitos também na crítica humorística da figura do ditador, o retrato satírico da maquinização do homem depois da Revolução Industrial. Para o que nos interessa aqui, não é por acaso que, entre tantas abordagens, entre tantos universos, lá está a criança. Anômalo e criança: a primeira das alianças.

De um outsider, passemos ao outro. Há algo de fascinante na figura da criança selvagem. Na criança que, ausente de quaisquer intervenções culturais, permanece alheia à educação. Rousseaunianamente, a criança selvagem é aquela que cresceu na selva, geralmente acompanhada de animais (e, por isso, vivendo como um deles). A criança que, capturada de seu hábitat, vem ao encontro da civilização (e de encontro a ela). No cinema, retiradas de experiências verídicas 
ou não, crianças-lobos, crianças-ursos tornaram-se protagonistas: desde o filme de Truffaut, a $O$ enigma de Kaspar Hauser, de Werner Herzog (1974), até Mogli, o menino lobo (Reitherman, 1967).

Em Truffaut, a criança selvagem é o anômalo: causa espanto, vertigem, curiosidade dos adultos e também das próprias crianças do vilarejo. A criança suja, mal vestida, de unhas mal cortadas, de cabelos longos e tão rebeldes quanto seu corpo: tirá-la da selva é tarefa árdua, requer táticas e estratégias; mantê-la na carruagem exige paciência e agilidade, não é fácil afastá-la do rio e das árvores, para onde ela insiste em fugir. É assim que, nos primeiros 15 minutos do filme, ela foge, escapa, resiste à prisão. A criança selvagem é aquela a que não se sabe dar nome, aquela cuja presença enigmática conduz seus responsáveis a abrigá-la naquilo do qual eles minimamente conseguem dar-se conta. "Idiota irrecuperável", como diz o mais famoso psiquiatra da época, Pinel - que marca também sua presença no filme, como um dos primeiros a analisar o caso do "sauvage d'Aveyron". Sua presença radical obriga-nos a pô-la, a situá-la em algum lugar, talvez apenas aproximativo, tangencial. Onde confiná-la? $\mathrm{Na}$ prisão? Na delegacia? Ou no Hospital Bicêtre, que no final do século VIII - período em que se passa o filme - era o asilo destinado a loucos e doentes mentais, "incuráveis"? Talvez no abrigo de surdos e mudos. Criança-anômalo e Itard (o médico, responsável pelo menino): a segunda aliança.

Há várias formas de descrever e de pensar o corpo desse selvagem. Após ser capturado, o menino é levado ao professor-doutor Itard e ao psiquiatra Pinel para exames: contata-se que ele mede $1 \mathrm{~m} 39 \mathrm{~cm}$ de altura, tem pele fina, cor escura, rosto oval, olhos negros, grandes pestanas, boca média, língua normal e bem distinta, dentição normal. Os observadores calculam ainda que ele deve ter entre 11 e 12 anos. No momento da apreensão, ele tinha 4 cicatrizes no braço esquerdo, no ombro e na perna direita, e umas 15 cicatrizes, arranhốes e rasgóes pelo resto do corpo, a maior parte devida a mordeduras de animais. Tinha ainda uma cicatriz diferente das outras no pescoço, uma sutura de $40 \mathrm{~mm}$, que parecia ser um corte provocado por instrumento afiado. A hipótese colocada pelos médicos foi a de que o selvagem deveria ter tido necessidade de matar animais para sobreviver. "Os que o abandonaram devem ter querido assassiná-lo”, afirma o professor.

Spinozamente, contudo, sabe-se que "é só num encontro que um corpo se define” (Silva, 2002, p. 53). É só no encontro com Dr. Itard 
que Victor pode ser Victor no sentido de ter agora um nome, de ser esse e um não outro qualquer), que pode ser corpo-resistência, que pode ser corpo-defesa, corpo-experimento, mas também corpo-rejeição. "Individualmente, isoladamente, um corpo tem pouco interesse" (idem, p. 53-54). É tão-somente por conta do encontro com Dr. Itard que podemos ver, levando em conta as disposiçôes do jogo, do que Victor é capaz. Se as disposições fossem outras, outras capacidades, outras potencialidades estariam, por certo, ainda por se fazer e por se definir. Tudo o que faz aqui "é pela primeira vez", como diz o médico Itard, responsável pelo menino.

Antes de ser corpo-métrico, mensurável, dado, importa-nos destacar esse corpo que agora se esforça para assumir outra forma de comunicação. Se alguma medida interessa é a da sua velocidade: aquela com que, após satisfazer o desejo de seu professor-doutor em unir o objeto-tesoura à figura que lhe corresponde ou à palavra que o substitui (como um dos muitos exercícios que são propostos ao menino), Victor joga-se no chão e atira tesoura, desenho e palavras ao longe. "As crianças são rápidas porque sabem deslizar entre" (Deleuze \& Parnet, 1998, p. 42; grifos meus). Se alguma medida interessa é esta, do deslizar entre: entre o corpo (a ser) educado e o corpo selvagem. Em sua velocidade, Victor suspende as expectativas em torno da noção de progresso: ele "evolui" por um lado e recua por outro. Encaixa perfeitamente a tesoura-objeto na tesoura-palavra (escrita no quadro-negro), mas ao mesmo tempo rompe com a união entre palavras e coisas que buscam definir ele mesmo, na condição de criança.

Em $O$ garoto, Carlitos é surpreendido com o choro de um bebê no meio de um beco. Ela pega o menino, do qual, porém, logo tenta se livrar: tenta dá-lo a uma mulher que passa à sua frente, a um mendigo que, bêbado, mal percebe o que está a se passar e, por fim, tenta deixá-lo ali mesmo, onde o encontrou. Em função da exigência do policial, que lhe pede explicaçôes para tal ato, ele se vê obrigado a recolher o menino e assumir como "seu". Neste primeiro momento do filme, criança rejeitada e criança acolhida coexistem e concorrem entre si. Cinco anos depois, no encontro com o vagabundo, o menino John aprende o gingado, a malícia, a ironia que, do alto de seus 5 anos, já lhe permite lidar com policiais ou, ainda, permite-lhe driblar o contador de gás. Do encontro com Carlitos, a brincadeira de atirar pedras 
nas janelas da vizinhança ganha outro sentido: ela serve agora para ocupar um limite indiscernível entre brincadeira e trabalho: John quebra as vidraças para, logo em seguida e estrategicamente, Carlitos passar pela frente da casa da "vítima" vendendo placas de vidro. E é dessa velocidade que aqui falamos: do espaço entre o cúmplice infantil, imitador do adulto, para aquele que também não deixa de ser o corpo-anjo, corpo-sonho na imaginação de Carlitos. Numa das sequências mais belas do filme, Carlitos, desesperado com o desaparecimento do menino, cochila na sarjeta. É então que somos transportados para seus sonhos: ele sonha com o céu, com o paraíso, com o "país das maravilhas" (dreamland, como nos sugerem as tradicionais legendas fixas dos filmes mudos). Em seu sonho, o beco onde moram é todo adornado de flores, crianças, animais e adultos - inclusive os policiais, os quais Carlitos tanto teme - cantam e dançam com suas harpas e asas e roupas brancas: são agora todos anjos, com exceção do sonhador. Aqui, nada de uma inocência óbvia de a criança transformar o adulto em anjo. Antes disso, John pega Carlitos pela mão e juntos vão fazer compras (shopping): é assim que também Carlitos compra, ele mesmo, suas próprias asas.

O encontro, neste sentido, é o que permite que as crianças Victor e John afirmem e coloquem em exercício suas forças. Não é de afetos que estamos falando, mas do poder de afetar. Não é de uma relação de carinho, tampouco de familiaridade, de algo que viria do exterior para sacudir o outro, em sua passividade, mas tão-somente da mobilização de forças as quais, em seu exercício, mostram-se profícuas para a capacidade, para a potência do agir. Em uma (ou duas) palavra (palavras): criação, invenção de formas de agir. E, enfim, quando criança-corpo se torna criança-acontecimento.

Victor não se torna "educado", mas também não persiste como "selvagem". Itard não se torna "professor", nem permanece como "médico" do menino. Da mesma forma, "Carlitos" deixa de ser o solitário, mas também não é pai. John deixa de ser órfão, mas também não é filho. É nesse espaço nascido da relação entre ambos que emerge esse entre-lugar indiferenciado, aquele que se afasta da designação e, justamente, do reconhecimento. Não ser nem uma coisa nem outra, mas, ao mesmo tempo, ser as duas. Os filmes, portanto, não se resumem a propor uma evolução entre estados (de selvagem a educado, 
de solitário a patriarcal), mas, ao contrário, apresentam-nos as involuções (Deleuze \& Guattari, 2002) ente os termos que estão o tempo inteiro em jogo. É esse movimento, pois, que é criador - a involução é criadora, diz-nos Deleuze -, pois entre os estados há um tanto ainda para se inventar (nos estados, nada se inventa, eles estão lá, dados). A criança não é animal, ela torna-se (devém) animal, assim como selvagem não é a criança, ele torna-se criança (devémcriança). ${ }^{2}$

Cabe entender que tais indescidibilidade e indiscernibilidade só são possíveis por estarmos falando do encontro com o anômalo. Ser e não ser, todo o tempo, ao mesmo tempo. Se em $O$ menino selvagem trata-se de reinventar um novo vocabulário para quem, aparentemente, até agora "ouve, mas não escuta; olha, mas não vê", em $O$ garoto trata-se de criar modos de ser criança no seio do espaço vazio entre o órfão e o cúmplice imitador.

Como criar esse espaço, ou, como criar nesse espaço? Com que elementos contar? Universos inteiramente apartados daqueles vivenciados por Victor na selva são agora postos em sua frente: caderno, tesoura, giz, quadro-negro, leite, pratos, colher. Agora, ele deve inserir, unir de algum jeito estes àqueles que já lhe são familiares: água, lua, sol, chuva, paisagem. Melhor dizendo, não se trata aqui de união, mas de composição. A união dos campos de multiplicidades dá-se pela preferência lírica de sempre beber água no copo somente em frente da janela. Ao som de Vivaldi, olhamos o menino olhar: a janela é aqui o lugar de onde ele pode ver, ao longe, as árvores que até ontem eram as únicas escadas que ele conhecia. Outro tipo de nascimento faz-se na imagem do cinema: outro corpo, não mais aquele nu, que anda de quatro, mas aquele que agora, com sapatos, esforça-se para andar ereto. Não mais os gritos mudos, onde toda a face se move para exprimir aquilo para o qual não tem voz, mas um grito ainda baixo, que se empenha ao máximo para dizer "lait" (leite). Não mais as mãos vorazes que levam a comida à boca, mas aquelas que, trêmulas, sentem dificuldade em pegar uma faca. Nenhuma dessas ações é realizada plenamente: quando volta a andar de quatro, não é mais nu, mas com as vestimentas que lhe foram dadas; quando toma o prato de sopa, é a colher que ele agarra faminto (a fome, portanto, é da colher, do manuseio com aquele objeto meio estranho, 
meio familiar). É em função do encontro e da composição ou, melhor dizendo, do choque entre multiplicidades que o campo aberto de possibilidades ganha existência. Unir, juntar os campos? Rejeitar o anterior e aceitar o novo, de forma tranquilizadora para aqueles que assistem? Não, desfilar entre, organizar composições entre eles: é essa a opção que as crianças cinematográficas nos apresentam.

No caso de $O$ garoto, a criança oscila entre sua condição de órfã, criança-bilhete ("por favor, ame e cuide desta criança órfă", escrevera a mãe no papel depositado ao lado do menino), e criança responsável. A pequena estatura dificulta o acesso ao fogão para preparar o café da manhã, mas também facilita quando tem de fugir e esconder-se dos policiais com Carlitos. As mãos que fazem o almoço são as mesmas que, tanto quanto as orelhas, devem ser inspecionadas para certificar-se de que estão limpas. A mesma criança que, com as mãos na cintura, faz Carlitos sair da cama pela manhã para tomar café é aquela a quem se obriga a rezar antes das refeições. Infantilidade genuína composta com uma suposta "adultez" dá margem aqui para a criação de uma criança que não se localiza nem num polo, nem no outro.

Quase final do filme, o menino adoece e Carlitos vê-se obrigado a providenciar cuidados médicos. O médico vai até a casa dos dois, examina John e, ao saber que ele não era filho de Carlitos, sai furioso do recinto, dizendo que o menino "precisa de cuidados apropriados". $\mathrm{Na}$ sequência, os responsáveis pelo orfanato da cidade vêm buscar John, em razão da denúncia feita pelo médico. Dramaticamente, eles são separados, mas não sem resistência. O menino, localizado num canto da casa, assiste à briga corporal entre Carlitos e os homens do orfanato, e chega a bater neles com um martelo. Agora com reforços, a tarefa de retirar o menino da casa torna-se mais fácil, e também mais dolorosa. Vemos o menino em close, já no caminhão do orfanato, chorando e chamando por Carlitos. Carlitos consegue fugir e, cambaleante pelos tetos das casas, vai ao encontro do caminhão, buscar o menino de volta. Por meio dessa sequência, vemos que a criança, ela mesma, faz vacilar a posição de anomalia de Carlitos, até então um homem solitário. Ele abraça John, beija-o e chora. Por um momento, é o anômalo que precisa fazer aliança com a criança para ampliar os limites de sua própria multiplicidade. 


\section{Considerações finais}

A partir dos filmes $O$ menino selvagem e $O$ garoto, busquei, neste texto, analisar os materiais a partir de conceitos que me auxiliassem a não resumir as crianças à ordem do mesmo. Ou seja, ao articular multiplicidade, encontro (ou composição) e função anômalo com as imagens cinematográficas, interessou-me enfatizar os espaços vazios nos quais elas se moviam para o exercício de criar diferenciadas formas de ser - formas jamais reconhecíveis ou passíveis de serem reunidas com outras, a não ser sob a égide da invenção. Seria possível até pensar (reunir) as crianças em torno dos conceitos que sustentam a discussão, mas aquilo que deles deriva dificilmente é agrupável. É disso, portanto, que trata a rejeição à categoria do mesmo: poderíamos supor um movimento no qual Victor, o menino selvagem, fosse apenas uma metáfora para aquilo que escola, família, cultura fazem com as crianças: domar, tratar, normalizar. $\mathrm{Ou}$, ainda, aquilo que a presença de Carlitos faz com John: acolher, dar-lhe uma família, um lar. Seguramente, estes seriam caminhos legítimos. No entanto, meu interesse esteve radicado não na descrição de imagens-corpo, que, num primeiro momento, fizeram-se massa confusa, para depois tornarem-se reconhecíveis e semelhantes entre si, no interior de um conjunto maior que responderia pelo nome de "crianças". Ao pensar as crianças dos filmes a partir de uma perspectiva do encontro, da composição e como sendo atravessadas por uma função anômalo, busquei somente efetuar um movimento que passasse do confirmativo "é assim" para aquele, talvez provocativamente, do "e se fosse assim?" (Silva, 2002, p. 53). E se, para além de domadas, educadas, familiares, as crianças pudessem ser outra coisa? Tal como as "mulheres de Picasso", ressaltadas por Tomaz Tadeu da Silva, trata-se também aqui de crianças heteróclitas, que suspendem qualquer noção de reconhecimento ou de totalização e se tornam, portanto, resistentes à identificação. Victor e o garoto são, eles mesmos, movimentos de dissolução: "a cada olhada, um rosto diferente" (idem, p. 49).

Assim, concluo afirmando que a própria criança que irrompe na tela, nesses filmes específicos, não é da ordem do exemplo dos conceitos que discuto: ela mesma, em sua condição de imagem cinematográfica, é o que constitui os conceitos. Os filmes servem-nos de base para algo que, de imediato, é insubordinável à identificação e à apreensão derradeira. O que importou, portanto, foi transformarmos sutilmente 
a afirmação de que a criança é: aqui ela simplesmente interessa na medida em que nos mostra como efetivamente ela se torna isso que é - mesmo que, num piscar de olhos, ela se torne, mais uma vez, uma outra coisa.

Recebido em maio de 2008 e aprovado em dezembro de 2008.

\section{Notas}

1. A pesquisa da qual este trabalho deriva contou com financiamento do CNPq (bolsa de doutorado) e da CAPES (bolsa de estágio de doutorado no exterior).

2. “Devir não é certamente imitar, nem identificar-se; nem regredir-progredir; nem corresponder, instaurar relações correspondentes; nem produzir (...). [Devir] não nos conduz a 'parecer', nem 'ser', nem 'equivaler', nem 'produzir'” (Deleuze \& Guattari, 2002, p. 19).

\section{Referências}

BAZIN, A. Charlie Chaplin. Paris: Petite Bibliothèque des Cahiers du Cinéma, 2000.

DELEUZE, G. A imanência: uma vida... Educação \& Realidade, Porto Alegre, v. 27, n. 2, p. 10-18, jul./dez. 2002.

DELEUZE, G.; GUATTARI, F. 1730: devir-intenso, devir-animal, devir-imperceptível... In: Deleuze, G.; Guattari, F. Mil Platôs: capitalismo e esquizofrenia. São Paulo: Editora 34, 2002. v. 4, p. 11-113.

DELEUZE, G.; GUATTARI, F. 1914: um só ou vários lobos. In: Deleuze, G.; Guattari, F. Mil Platôs: capitalismo e esquizofrenia. São Paulo: Editora 34, 2000. v. 1, p. 39-52.

DELEUZE, G.; PARNET, C. Diálogos. São Paulo: Escuta, 1998.

HÉBER-SUFFRIN, P. O "Zaratustra" de Nietzsche. Rio de Janeiro: Zahar, 2003.

LECLERQ, S. Deleuze e os bebês. Educação \& Realidade, Porto Alegre, v. 27, n. 2, p. 19-29, jul./dez. 2002. 
Sobre crianças e encontros: singularidades em jogo na estética cinematográfica

MERTEN, L.C. Cinema: entre a realidade e o artifício. Porto Alegre: Artes e Ofícios, 2005.

SILVA, T.T. A arte do encontro e da composição: Spinoza + Currículo + Deleuze. Educação \& Realidade, Porto Alegre, v. 27, n. 2, p. 4758, jul./dez. 2002.

SILVA, T.T. Um plano de imanência para o currículo. In: SiLVA, T.T.; Corazza, S.M.; Zordan, P.G. Linhas de escrita. Belo Horizonte: Autêntica, 2004. p. 127-205.

TRUfFAUT, F. Préface. In: Bazin, A. Charlie Chaplin. Paris: Petite Bibliothèque des Cahiers du Cinéma, 2000. p. 9-13.

Filmes referidos

AGRESTI, A. Valentin. Argentina, 83 min., 2002.

BABENCO, H. Pixote, a lei do mais fraco. Brasil, 127 min., 1981.

BOORMAN, J. Esperança e glória [Hope and glory]. Inglaterra, 107 min., 1987.

CARO, N. Encantadora de baleias [Whale rider]. Nova Zelândia, 105 min., 2003.

CHAPLIN, C. O barba azul [Monsieur Verdoux]. Estados Unidos, 124 min., 1947.

CHAPLIN, C. O circo [The circus]. Estados Unidos, 69 min., 1928.

CHAPLIN, C. O garoto [The kid]. Estados Unidos, 79 min., 1921.

CHAPLIN, C. O grande ditador [The great dictator]. Estados Unidos, 124 min., 1940.

CHAPLIN, C. Luzes da cidade [City lights]. Estados Unidos, 87 min., 1931.

CHAPLIN, C. Tempos modernos [Modern times]. Estados Unidos, 87 min., 1936. 
CHAPLIN, C. Uma vida de cão [A dog's life]. Estados Unidos, 88 min., 1918

DE SICA, V. Vitimas da tormenta [Sciuscia]. Itália, 95 min., 1946.

FEYDER, J. Visages d'enfants. Bélgica, 90 min., 1925.

HALLSTRÖM, L. Minha vida de cachorro [Mitt Liv Som Hund]. Suécia, 101 min., 1985.

HERZOG, W. O enigma de Kaspar Hauser [Jeder für Sich und Gott Gegen Alle]. Alemanha, 109 min., 1974.

KIAROSTAMI, A. Onde fica a casa do meu amigo? [Khaneh-Ye Dust Kojast?]. Irã, 90 min., 1987.

LAMORISSE, A. O balão vermelho [Le ballon rouge]. França, 40 min., 1956.

LAUZON, J-C. Leolo [Léolo]. França/Canadá, 110 min., 1992.

MALLE, L. Adeus, meninos [Au revoir, les enfants]. França, 102 min., 1987.

MALLE, L. O balão branco [Badkonake Sefid]. Irã, 90 min., 1995.

REITHERMAN, W. Mogli, o menino lobo [The jungle book]. Estados Unidos, 78 min., 1967.

ROSSELLINI, R. Alemanha, ano zero [Germania, anno zero]. Itália, 80 min., 1947.

SPIELBERG, S. A.I. - Inteligência artificial [A.I. - Artificial intelligence]. Estados Unidos, 146 min., 2001.

TARKOVSKY, I. A infância de Ivan [Ivanovo Detstvo]. União Soviética, 95 min., 1962.

TORnATORE, G. Cinema Paradiso [Nuovo Cinema Paradiso]. Itália, 155 min., 1988.

TRUFFAUT, F. O menino selvagem [L'Enfant sauvage]. França, 95 min., 1970.

VAJDA, L. Marcelino, pão e vinho [Marcelino pan y vino]. Itália/ Espanha, 91 min., 1954. 


\section{Súmula dos filmes analisados}

O garoto

Título original: The kid

Direção: Charles Chaplin

Ano: 1921

País de origem: EUA

Duração: $79 \mathrm{~min}$.

Sinopse: O garoto, feito em 1921, conta a história de uma mãe solteira que pela impossibilidade de poder criar o filho recém-nascido o deixa em um banco de um automóvel luxuoso para que alguém o ache e cuide dele, mas o automóvel é roubado e os ladrões abandonam o bebê em uma viela. $\mathrm{O}$ vagabundo Carlitos encontra a criança e tenta primeiramente a todo custo se livrar dela, mas não consegue em razão de circunstâncias adversas; com o passar do tempo vai se afeiçoando à criança e passa a criá-la. Ao mesmo tempo a mãe do bebê se arrepende e começa a procurá-lo até que descobre que o carro foi roubado e que nunca mais irá encontrar seu filho. $\mathrm{O}$ garoto foi o primeiro grande sucesso da carreira de Chaplin, que à época ainda estava contratado do estúdio First National. Apesar de atrelado ao estúdio o diretor consegue dirigir e atuar, também escrever e montar o filme. A trilha sonora, também composta por Chaplin, foi feita apenas em 1971. Considerado uma das muitas obras-primas de Chaplin, O garoto trouxe para a época a utilização do sonho como uma inovação. $\mathrm{O}$ filme traz o primeiro atormirim que ficou célebre, Jackie Coogan, que rouba a cena de Chaplin em alguns momentos do filme.

O menino selvagem

Título original: L'enfant sauvage

Direção: François Truffaut

Ano: 1969

País de origem: França

Duração: $88 \mathrm{~min}$.

Sinopse: Em 1797, um menino é encontrado na floresta de Aveyron, vivendo como selvagem, sem saber andar, falar ou se expressar. Ele então fica sob os cuidados do médico Jean Itard, que acredita poder sociabilizá-lo. Itard conta com a ajuda de Madame Guérin, sua governanta, para educar o menino e ajudá-lo a se comunicar por meio de sinais. Por várias vezes, o menino tenta escapar, mas acaba se envolvendo numa relação filial com o jovem doutor. História baseada em fatos reais que ocorreram nos fins do século XVIII. 